Article

\title{
Victims of Violence: The Forced Sterilisation of Women and Girls with Disabilities in Australia
}

\author{
Laura Elliott \\ Graduate student, Melbourne Law School, University of Melbourne, 185 Pelham St, Carlton, VIC 3053, \\ Australia; lelliott1@student.unimelb.edu.au
}

Received: 17 May 2017; Accepted: 21 June 2017; Published: 4 July 2017

\begin{abstract}
This paper considers the issue of forced sterilisation of women and girls with disabilities in the Australian context. It examines the history and ideological underpinning of this practice, the current Australian regime and the present rationales for court or tribunal authorisation of a sterilising procedure. It is by no means an exhaustive coverage, but aims to critically analyse the current system and make recommendations for reform of Australian law and policy. This paper ultimately concludes that the practice of forced sterilisation in Australia should be criminalised, save for exceptional circumstances.
\end{abstract}

Keywords: disability; human rights; sterilisation; violence; medical procedures; legal capacity; consent; women; girls; Convention on the Rights of Persons with Disabilities

\section{Introduction}

In recent years, the forced sterilisation of people with disabilities in Australia has been a topic of considerable focus and debate, both nationwide and internationally. Despite a barrage of recommendations from people with disabilities, their allies and international bodies to criminalise forced sterilisation, this practice is still legal and sanctioned in Australia. This paper will focus on the forced sterilisation of girls and women as they are disproportionately affected by this procedure (Frohmader 2013). It is an intersectional issue and a gendered practice, the 'result of both gender and disability-based discrimination' (Australian Human Rights Commission 2013, p. 3).

The current legislative and policy framework in Australia permits gross violations of human rights and dignity to occur on a regular basis. Furthermore, consistently authorising this form of violence puts Australia in breach of its international human rights obligations. As such, this paper contends that the involuntary sterilisation of women and girls with disabilities in Australia should be criminalised in all circumstances, save for exceptional situations in which an individual is completely unable to make a decision or, for minors, where there is a serious risk to an individual's health or life. The inadequacy of the current system necessitates a new regime that aligns more closely with the social model of disability: rather than viewing the individual as the problem, attention should be paid to reducing the societal or environmental barriers that lead to the factors that underpin the justifications for the sterilisation of women and girls with disabilities (Shakespeare 2002).

Section 2 of this paper provides an overview of forced sterilisation in Australia, including its recent history and socio-political basis. Section 3 details Australia's human rights obligations under international law, and examines how specific provisions under the Convention on the Rights of Persons with Disabilities (Convention on the Rights of Persons with Disabilities 2008a) (CRPD) relate to the practice of forced sterilisation. Sections 4 and 5 outline the current Australian legislative framework in which applications for forced sterilisation of women and girls can be authorised by a court or tribunal and the rationales for authorising forced sterilisation. This background paves the way for a critical analysis of the current Australian system, which is provided in Section 6. This section addresses 
the ultimate question: should the forced sterilisation of women and girls with disabilities be made illegal in Australia? After asserting that it should, Section 7 details the author's recommendations for legislative and policy reform in Australia.

The forced sterilisation of women and girls with disabilities in Australia must be put to an end. It is time for the Australian Government to jettison their callous indifference towards the life-long impact on individuals that are affected by this practice and bring Australia in line with its human rights obligations.

\section{Overview of Forced Sterilisation in Australia}

Women with Disabilities Australia (WWDA) have defined forced sterilisation as the 'performance of a procedure which results in sterilisation in the absence of the free and informed consent of the individual who undergoes the procedure' (Frohmader 2013, p. 22). This definition is inclusive of situations in which sterilisation has been authorised by a third party such as a parent, legal guardian, court, tribunal or judge (Frohmader 2013). The CRPD defines persons with disabilities as those who have 'long-term physical, mental, intellectual or sensory impairments which in interaction with various barriers may hinder their full and effective participation in society on an equal basis with others' (Convention on the Rights of Persons with Disabilities 2008a, article 1).

It is broadly recognized that sterilisation is a process or act that renders a person unable to produce children' (Senate Community Affairs References Committee 2013, p. 6). Various kinds of procedures constitute a sterilising practice. These include permanent or irreversible sterilising procedures, such as a hysterectomy (removal of the uterus and sometimes the cervix, fallopian tubes, ovaries or part of the vagina), tubal litigation (blocking or closing of the fallopian tubes) and endometrial ablation (laser technology used to destroy the uterine lining for purposes of stopping menstruation). This definition also includes non-permanent contraceptive measures such as oral contraceptives, diaphragms, intrauterine devices and long acting reversible contraceptives such as injections (Depo Provera) and implants (Implanon) (Senate Community Affairs References Committee 2013).

For over 20 years, disability advocates have been demanding the Australian Government undertake comprehensive reforms to stop the involuntary and coerced sterilisation of women and girls with disabilities, and develop policies and programs that allow women and girls with disabilities to be afforded respect of their human rights on an equal basis with others (Frohmader 2013). There have been numerous studies undertaken and reports published recommending reform in the sterilisation sphere in Australia. In 1994, the Family Law Council (Family Law Council 1994) concluded that a uniform and consistent approach was needed for all children regardless of their geographical location within Australia. The Council also stated that sterilisation of a child should only be authorised if it is necessary to save the child's life or prevent serious damage to their health (Family Law Council 1994). The Australian Human Rights Commission published reports in 1997 and 2001 propounding that the number of sterilisations being performed on children and women with disabilities in Australia was greater than those that had been authorised by a court or tribunal and that it was clear that the law was failing to protect individuals from involuntary sterilisation (Brady and Grover 1997; Brady et al. 2001). These reports did trigger some minor changes, such as Medicare amending their policies to require that claims for sterilisation of children be accompanied by a court order or medical details of the need for the procedure (Brady et al. 2001). However, there have been no substantial changes made to legislation or policy regarding the forced sterilisation of women and children with disabilities.

The Australian Government has spent a considerable amount of time investigating the issue of forced sterilisation of women and girls with disabilities. The main concern of public policy in this area has focused on "piecemeal development of mechanisms, protocols and guidelines in an attempt to 'minimise the risk of unauthorised sterilisations occurring'" (Standing Committee of Attorneys-General 2004 as cited in Frohmader 2013, p. 26). In December 2000, the Government tabled in the Senate the report 'Sterilisation of women and young girls with an intellectual disability' which, on the basis of data from the Australian Institute of Health and Welfare, submitted that, between 1993 and 1999, there 
were few sterilisations of girls with disabilities in Australia (Senate Community Affairs References Committee 2013). In reality, there has been a substantial dearth of quantitative research undertaken in regards to forced sterilisation. Brady et al. (2001) reported in 2001 that 28 authorisations occurred between 1992 and 1998, with eight rejections. In contrast, Brady and Grover (Brady and Grover 1997) adduced Health Insurance Commission data to claim that at least 1045 women and girls had been sterilised during the same period, and noted that there would be others who were treated in public hospitals without attracting Medicare benefits. This lack of concrete data has led to considerable uncertainty around the exact frequency of the practice of forced sterilisation in Australia, a concern that has not been addressed by the Australian Government. In August 2003, Australian Governments, through the then Standing Committee of Attorneys-General (SCAG) agreed that a nationally uniform framework for the authorisation of the sterilisation of children was required (Frohmader 2013). From 2003 to 2007, notwithstanding strong resistance from human rights and disability advocates, the SCAG developed proposed legislation that aimed to regulate the authorisation of sterilisation of children with a 'decision-making disability', rather than make the practice of sterilisation of children illegal (Frohmader 2013). In November 2006, the SCAG released a draft bill that set out procedures that jurisdictions could adopt in authorising the sterilisation of children who have an intellectual disability $^{1}$. Ultimately, however, the SCAG abandoned this draft Bill in 2008, declaring that there would be limited benefit from developing model legislation. Instead, the Government 'agreed to review current arrangements to ensure that all tribunals or bodies with the power to make orders concerning the sterilisation of minors with an intellectual disability are required to be satisfied that all appropriate alternatives to sterilisation have been fully explored and/or tried before such an order is made' (Standing Committee of Attorneys-General 2008, p. 7).

There is no evidence to date that those reviews were conducted. In 2009, the Australian Government formally declared to the UN that a comprehensive review undertaken in Australia showed that sterilisations of children with an intellectual disability had declined since 1997 to very low numbers (Australian Government 2009 as cited in Frohmader 2013). However, there was again no evidence to support that a comprehensive review had been undertaken (Frohmader 2013).

Furthermore, the issue of forced sterilisation in Australia has received ample international scrutiny. Since 2005, UN treaty monitoring bodies have continuously and formally recommended that the Australian Government enact uniform national legislation outlawing the sterilisation of girls, except where there is a serious threat to their health or life, and adult women with disabilities without their free and informed consent. These bodies include the Committee on the Convention on the Rights of the Child (Convention on the Rights of the Child 1990) (CRC), the Committee on the Convention on the Elimination of all Forms of Discrimination Against Women (CEDAW) (Convention on the Elimination of all Forms of Discrimination against Women 1981) and the UN Human Rights Council (Committee on the Rights of the Child 2012; Committee on the Elimination of Discrimination against Women 2010; Committee on the Rights of the Child 2005; UN General Assembly Human Rights Council 2011). The Australian Government is yet to comply with any of the recommendations (Frohmader 2013). In 2011, after WWDA lodged a formal complaint, UN Special Rapporteurs Anand Grover and Rashida Manjoo wrote to the Australian Government seeking a formal response on the issue of forced sterilisation (Frohmader 2013, Appendix 2). The Government's response confirmed the absence of a uniform national approach to the authorisation of sterilisation of women and girls with disabilities, and reinforced the Government's view that there are situations in which it can and should be permitted (Frohmader 2013, Appendix 3). International medical bodies, such as the International Federation of Gynaecology and Obstetrics, World Medical Association, International NGO Council on Violence against Children and the $\mathrm{WHO}$, have also become involved, developing new protocols and calls for action to eliminate the practice of forced sterilisation (World Medical Association and the

1 Children with Intellectual Disabilities (Regulation of Sterilisation) Bill 2006. 
International Federation of Health and Human Rights Organisations 2011; International NGO Council on Violence against Children 2012; World Health Organisation 2014). Despite the abundance of debate and discussion around this issue, the forced sterilisation of women and girls with disabilities remains legal and practiced in Australia (Frohmader 2014).

It is also worrying to note that, often due to the cost and formality of court processes in Australia, families and carers wishing to have an individual with a disability sterilised are starting to circumvent the formal procedures. In a 2003 Four Corners report, Peter and Dot King spoke of how they had their 15-year-old daughter Trish sterilised in secret. She was booked into the hospital under her mother's name, and the procedure was carried out without any substantial questions being asked (ABC 2003a). Dr and Mrs Carter, in their submission to the recent Senate inquiry, stated that they 'are aware of instances where parents have taken their daughters to Thailand or New Zealand to have a hysterectomy because their request to have a hysterectomy performed in Australia was rejected' (Carter and Carter 2013, p. 3). It is clear that the current law is continually failing to protect vulnerable individuals at risk of forced sterilisation in numerous ways and that steps need to be taken to ensure that the rights of these individuals are protected on an equal basis with others.

\section{International Obligations}

WWDA have declared that 'forced sterilisation clearly breaches every international human rights treaty and declaration to which Australia is a party' (Frohmader 2013, p. 70). These include the CRPD, the CRC, the CEDAW, the International Convention on Civil and Political Rights (International Convention on Civil and Political Rights 1976), the International Covenant on Economic, Social and Cultural Rights (International Covenant on Economic, Social and Cultural Rights 1976) and other key international and national standards and frameworks (Frohmader 2013). This report will focus on the CRPD, in particular how allowing involuntary sterilisation to continue puts Australia in breach of articles 12 and 16.

Australia ratified the CRPD on 17 Australia 2008 and the Optional Protocol on 21 August 2009. It must be noted that in entering into the treaty, Australia declared its view that the Convention allows for substituted decision-making and compulsory medical treatment (Convention on the Rights of Persons with Disabilities 2008b). Whilst the Committee on the CRPD (the Committee) may make recommendations that the Government in Australia take specific action, the CRPD has no binding effect in Australia. To date, no domestic legislation has been enacted that protects the rights affirmed under the CRPD. Whilst bodies such as the Committee can be influential in shaping Australia's policy, it is ultimately the Australian Government's responsibility to enact legislation to enforce Australia's international obligations.

\subsection{Article 12: Equal Recognition before the Law}

Article 12 provides that persons with disabilities have the right to recognition everywhere as persons before the law. This includes recognising that persons with disabilities enjoy legal capacity on an equal basis with others in all aspects of life. This positive right requires States to take appropriate measures to provide access for persons with disabilities to the support they may require in exercising their legal capacity. It also requires States to ensure that effective safeguards are in place in all measures that relate to the exercise of legal capacity to prevent abuse of human rights (Convention on the Rights of Persons with Disabilities 2008a).

Numerous stakeholders hold the view that article 12 prohibits substituted decision-making. The Committee has clearly stated that article 12 mandates the replacement of substituted decision-making systems with supported decision-making (Committee on the Rights of Persons with Disabilities 2011). WWDA submit that article 12 means that 'an individual's right to decision-making cannot be substituted by decision-making of a third party, but each individual without exception has the right to make their own choices and to direct their own lives, whether in relation to living arrangements, medical treatment or family relationships' (Frohmader 2013, p. 71). People With Disabilities Australia 
(People with Disabilities Australia 2013, p. 18) argue that the 'implementation of article 12 requires establishing supported decision-making alternatives to substituted decision-making regimes [and] effective safeguards to be introduced in relation to supported decision-making arrangements to prevent abuse in accordance with international human rights law'. Flynn and Arstein-Kerslake (Flynn and Arstein-Kerslake 2014) also propound that article 12 requires a proactive approach from state parties, where measures are put in place to support individuals in the exercise of their legal capacity, rather than assessing their mental capacity before their decisions will be legally recognized. This article therefore prohibits substituted decision-making regimes, such as that provided in the Guardianship and Administration Act 1986 (Vic) ${ }^{2}$ (Guardianship Act) or at common law in relation to the sterilisation of girls with disabilities.

\subsection{Article 16: Freedom from Exploitation, Violence and Abuse}

Article 16 requires that States take all appropriate legislative, administrative, social, educational and other measures to protect persons with disabilities from all forms of exploitation, violence and abuse, including their gender-based aspects. It also compels States to provide information, education, assistance and support for persons with disabilities and their families on how to avoid, recognise and report instances of exploitation, violence and abuse. Further, it mandates that States put in place effective legislation and policies, including those focused on the protection of women and children, to ensure that instances of exploitation, violence and abuse against persons with disabilities are identified, investigated and, where appropriate, prosecuted (Convention on the Rights of Persons with Disabilities 2008a).

As will be argued later in this paper, forced sterilisation can be classified as a form of violence. Thus, article 16 requires state parties to take measures to protect individuals from this practice. This includes providing education and support and enacting legislation to prohibit occurrences of forced sterilisation. Under the CRPD, therefore, state parties are prevented from facilitating procedures, such as those in place in Australia, in which the practice of forced sterilisation can be lawfully authorised.

\subsection{Other Relevant Articles}

Article 23(1)(c) requires States to take effective and appropriate measures to eliminate discrimination against persons with disabilities in all matters relating to marriage, family, parenthood and relationships, on an equal basis with others, so as to ensure that persons with disabilities, including children, retain their fertility on an equal basis with others (Convention on the Rights of Persons with Disabilities 2008a). Allowing women and children with disabilities to be sterilised without their consent clearly violates this provision, as the same law does not affect, on an equal basis, women and girls without disabilities.

\section{Australian Legislative Framework and Court Processes}

Australia's international treaty obligations are given effect through federal, state and territory legislation. There is much disparity in the legislation and court processes between the states and territories. As such, this paper will focus solely on the Victorian jurisdiction.

\subsection{Girls with Disabilities}

In Victoria, jurisdiction has not been expressly conferred on any Australian court or tribunal to hear child sterilisation cases. The sterilisation of children with disabilities is dealt with by the common law following the leading decision in Secretary, Department of Health and Community Services (NT) $v$ JWB and SMB (1992) 175 CLR 218 (Marion's Case) ${ }^{3}$. In that case, the High Court heard an application for 
the sterilisation of a 13-year-old girl with an intellectual disability. Marion's parents, who brought the application, were concerned about fertility control and menstruation with its psychological and behavioural problems ${ }^{4}$. The High Court held that, in cases where the child is not 'legally competent', the Family Court is required to give approval before a child is sterilised, unless sterilisation occurs because of an appropriate 'therapeutic' procedure carried out to address an actual health issue (Office of the Public Advocate 2013, p. 6). This case confirmed that the Family Court's child welfare jurisdiction under section 67ZC of the Family Law Act 1975 (Cth) ${ }^{5}$ (Family Law Act) empowers the court to make orders for the sterilisation of a child (Senate Community Affairs References Committee 2013). It also established that it is only for the Courts to decide on such fundamental questions of human rights as the right to reproduce, rather than parents, carers or medical practitioners (Dowse 2004). There were two main reasons for this. Firstly, the risk of making the wrong decision is significant, and secondly, the consequences of a wrong decision would be particularly grave. ${ }^{6}$ Before making an order for sterilisation, the Family Court must be satisfied that two conditions are met. First, that the sterilisation is, in the circumstances of the particular case, in the child's best interests, and second, that alternative and less invasive procedures have failed or it is certain that no other procedure or treatment will work (Senate Community Affairs References Committee 2013). Sections 60CB to 60CG of the Family Law Act outline how a court is to determine what is in the child's best interests. However, it must be noted that these provisions were not designed specifically for sterilisation cases; rather, they were enacted to deal with situations in which matters such as where the child will live are being decided (Senate Community Affairs References Committee 2013). Therefore, in hearing child sterilisation cases, the Family Court will apply the general principles regarding the best interests and the welfare of the child in Part VII of the Family Law Act, the factors detailed in Marion's Case in determining that particular child's best interests, as well as the Family Law Rules 2004 (Cth) ${ }^{7}$ developed to govern applications for 'medical procedures'.

Marion's Case was thought to be progress in the human rights sphere, as it considered the rights of children with disabilities through a 'best interests' lens and aimed to prevent parents from being able to sterilise their child without an order of the court. One of the intentions of the decision was to prevent unnecessary sterilisations (Rhoades 1995; ABC 2003b). However, Marion was quickly deemed 'legally incapable' and at no point did any member of the proceedings attempt to understand what Marion's wishes were. This is a trend in most court decisions on sterilisation, and there has been negligible deliberation in the judgements over this issue compared to decisions in cases relating to children without a disability (Steele 2008). Furthermore, the majority of the High Court held that the views of the parents are a relevant consideration for the Family Court, and anticipated that the outcome in sterilisation cases would ordinarily coincide with their wishes ${ }^{8}$ (Rhoades 1995). The extent to which Marion's Case tangibly progressed the rights of people with disabilities is therefore debatable, as there was never any discussion of the empowerment of people with disabilities to make decisions. It has also been argued that judicial decisions following Marion's Case have failed to give full effect to its promise. There has been concern that the legal requirements set out in Marion's Case have not consistently been followed and that some sterilisations are being performed illegally with parent approval only, as opposed to court approval (Office of the Public Advocate 2013). Further, it has been said that within the medical practice the distinction between 'therapeutic' and 'non-therapeutic' sterilisations has become blurred (Naik 2012, p. 453). The Family Court has been criticised for effectively ignoring its own rhetoric regarding the rights of women and girls with disabilities and reverting to an archaic and discredited model (Rhoades 1995). It is clear that both legislative reform and greater guidance for

\footnotetext{
Secretary, Department of Health and Community Services (NT) v JWB and SMB (1992) 175 CLR 218 (Marion's Case). Family Law Act 1975 (Cth).

Secretary, Department of Health and Community Services (NT) v JWB and SMB (1992) 175 CLR 218 (Marion's Case).

Family Law Rules 2004 (Cth).

Secretary, Department of Health and Community Services (NT) v JWB and SMB (1992) 175 CLR 218 (Marion's Case), at p. 260.
} 
decision makers are required to ensure the rights of women and girls with disabilities do not continue to be violated.

\subsection{Women with Disabilities}

For women over 18 with disabilities, court proceedings differ across States and Territories. In Victoria, the Guardianship Act (s. 39) empowers the Victorian Civil and Administrative Tribunal (VCAT) to make an order giving consent to special medical treatment for persons 18 years of age or older who are incapable of giving consent to the proposed treatment. 'Special procedure' includes any procedure that is intended or is reasonably likely to have the effect of rendering a person permanently infertile (Guardianship Act, s. 3). A person is considered to be incapable of providing consent if he or she is incapable of understanding the general nature and effect of the proposed procedure or treatment, or is incapable of indicating whether or not he or she consents or does not consent to the carrying out of the proposed procedure or treatment (Guardianship Act, s. 36). If it is found that the person does not have capacity to consent, the court or tribunal is to decide whether to authorise the sterilization (Guardianship Act, s. 39).

The tribunal may consent to the carrying out of a special procedure only if it is satisfied that the person is incapable of giving consent and is not likely to be capable, within a reasonable time, of giving consent and the special procedure would be in the person's best interests (Guardianship Act, s. 42E). In determining a patient's best interests, the tribunal must take into account the person's wishes and the wishes of any relative, the consequences if the treatment is not performed, any alternative treatment available, the nature and degree of any significant risks associated with the treatment or any alternative treatment and whether the treatment is to be carried out only to promote and maintain the person's health and wellbeing (Guardianship Act, s. 38). By requiring the tribunal to consider the views of relatives, this legislation explicitly incorporates the opinions and needs of persons other than the individual concerned in the determination of their best interests (Senate Community Affairs References Committee 2013).

It is an offence subject to imprisonment for two years and/or a fine of up to $\$ 36,400$ for a registered practitioner to conduct a special procedure without tribunal consent (Guardianship Act, s. 42G). However, it is not an offence, or professional misconduct, for the registered practitioner to act in response to a medical emergency or in good faith reasonably believing that consent had been obtained (Guardianship Act, s. 42A). It is also an offence to purport to give consent to special medical treatment. A person who gives consent to treatment knowing that he or she is not authorised to do so is guilty of an offence subject to a fine not exceeding 20 penalty units (Guardianship Act, s. 42). In 2016 , this means the maximum fine would be around $\$ 3300$, hardly an excessive figure (Victorian State Government 2016).

Additional regulatory requirements in relation to sterilisation exist at the State and Territory level. States and territories have adopted the Australian Guardianship and Administration Council's Protocol for Special Medical Procedures (Sterilisation) ${ }^{9}$ (the Protocol), which applies to both women and girls and is intended to promote consistency in similar sterilisation cases regardless of the jurisdiction in which the case is heard. Phase 2 of the Protocol requires tribunals to adopt a two-stage inquiry process. First, the tribunal must consider whether an individual has the capacity to consent to sterilization (the Protocol, cl. 5.8). This involves determining whether the person understands the nature and effect of their decision, whether they are freely and voluntarily making a decision and whether they can communicate their decision in some way (the Protocol, cl. 5.11). However, even though the Protocol requires tribunals to consider capacity as a threshold question, it does not prohibit tribunals from hearing a case where it is determined that the individual does have capacity (Senate Community Affairs References Committee 2013). Second, before authorising a procedure, the tribunal must consider

9 Protocol for Special Medical Procedures (Sterilisation). 
whether sterilisation is required, in the sense that other options have been explored and decided against (the Protocol, cl. 5.17).

\section{Current Rationales for the Sterilisation of Women and Girls with Disabilities}

WWDA classifies the main contemporary justifications for the sterilisation of a woman or girl with a disability into four broad categories: the genetic/eugenics argument, the good of the state, community or family argument, the incapacity for parenthood argument and the prevention of sexual abuse argument (Frohmader 2013). These rationales are all strongly rooted in the medical model of disability. The medical model views disability as a deficiency or disorder that is a tragedy and causes dependence on others. It sees disability as an essential trait of the person (Parker 2012). Under this model, the focus is placed on 'diagnosis and treatment of what are seen as cognitive and adaptive deficits, measured against norms of intelligence and independent functioning' (Parker 2012, p. 522).

\subsection{The Genetic/Eugenic Argument}

Historically, the rationale for sterilisation of women and girls with disabilities was a pseudo-scientific theory called eugenics. The aim of sterilisation under the eugenics movement was to stop non-productive members of society from reproducing for the 'benefit' of the rest of society (Gallichan 1929 and Ford 1996 as cited in Spicer 1999). Whilst this justification has been eradicated from legislation in most countries, remnants of it still remain within the attitudes of some sectors of the community (Frohmader 2013). This argument centres on the misconceived fear that women with disabilities will produce children with undesirable genetic 'defects'. The contemporary version of this justification disguises itself behind a 'best interests' veil, attempting to smother any trace of its connections to the Nazi era and genetic 'cleansing'. A recent example is the 2004 case of $B H v C C H$ $[2004]^{10}$ FamCA 496 in which the Family Court authorised the sterilisation of a 12-year-old girl with an intellectual disability and Tuberous Sclerosis. There was a 50\% chance that any child she had would be born with Tuberous Sclerosis (TS). Although one in two people born with TS will lead a 'normal' life, the Court nonetheless considered that this was a factor weighing in favour of sterilisation.

\subsection{The Good of the State, Community or Family Argument}

This justification focuses on the 'burden' that women and girls with disabilities and their potentially disabled children place on the resources and services provided by the state and community (Frohmader 2013). It is also based on the burden of care that the management of menstruation and contraception places on families and carers due to 'conditions' such as challenging or unmanageable behaviour and hygiene issues (Steele 2008; Frohmader 2013). There have been numerous instances where the Court has authorised the sterilisation of women and girls with disabilities for menstrual management $^{11}$ (Attorney-General (QLD) v Parents (In Re S) (1989) 13 Fam Lr 660; Re Angela [2010] FamCA $98^{12}$; BH v CCH [2004] FamCA 496).

The most concerning aspect of this rationale is that it is being used to authorise sterilisations before the individual has even begun menstruating. In Re Angela [2010] FamCA 98, the Family Court authorised the hysterectomy of an 11-year-old girl with Rett Syndrome to prevent menstruation. In Re Katie (1995) 128 FLR 194, 13 a 15-year-old girl was sterilised at the onset of her menstruation. In Attorney-General (QLD) v Parents (In Re S) (1989) 13 Fam Lr 660 and Re M (An Infant) (1992) 106 FLR 433, ${ }^{14}$ 12-year-old and 15-year-old girls, respectively, were sterilised before they had begun menstruating. Stella Young has also divulged the story of how at the age of four, when being treated

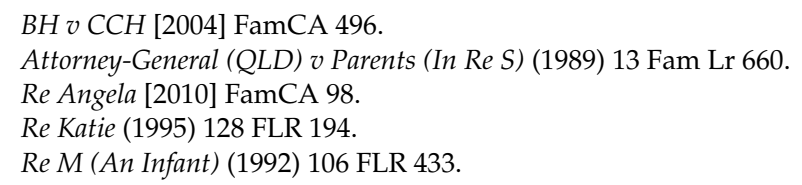


for a broken leg, her doctor had suggested to her parents that they perform a hysterectomy to prevent having to deal with the 'inconvenience of menstruation' in the future (Young 2013, p. 1).

As WWDA have promulgated, 'the denial of a young women's human rights through the performance of an irreversible medical intervention with long term physical and psychological health risks is wrongly seen as the most appropriate solution to the social problem of lack of services and support (Frohmader 2013, p. 42). Sterilisation is often easier, faster and less costly than providing the programs, services and supports to enable young women and girls with disabilities to obtain and understand information and competencies about their bodies, relationships, sex, safety and rights (Frohmader 2013). Evidence indicates that the concerns and problems that arise at the onset of menstruation of women and girls with disabilities are often the same types of concerns as for women and girls without disabilities (Brady and Grover 1997 as cited in Spicer 1999). It also indicates that even individuals with high support needs can be accommodated with approaches similar to those taken for non-disabled women (Frohmader 2013). When parents and carers are given the necessary resources and support, the justification of menstrual management loses credibility.

The flip side to this argument focuses on the loss of dignity and reduction in quality of life associated with an inability to manage menstruation. Carter and Carter (Carter and Carter 2013, p. 1) stated that, 'there are many moderate-severe intellectually disabled women who are extremely distressed due to their inability to cope with menstruation leading to loss of dignity'. They stress that menstruation can cause a significant reduction in quality of life and hence damage to an individual's emotional or psychological health. They give the example of instances where 'an intellectually disabled woman has remained in the bathroom at the supported employment with blood over her clothes, due to the onset of menstruation' (Carter and Carter 2013, p. 1).

\subsection{The Incapacity for Parenthood Argument}

This rationale is based on widely held societal attitudes that women with disabilities, especially intellectual disabilities, are incapable of being good parents. This ideology creates pressure to prevent pregnancy in women with disabilities (Frohmader 2013). Women with disabilities are often seen as perpetually child-like, asexual or over-sexed and therefore inadequate parents (Committee on the Rights of Persons with Disabilities 2013; STAR 1991). Stella Young touches on this misconception in her submission to the recent Senate inquiry, recounting how she was laughed at when telling a doctor that she was sexually active (Young 2013, p. 1).

In Australia, a parent with a disability is up to ten times more likely to have a child removed from their care than a parent without a disability (Victorian Office of the Public Advocate 2012). Often, the removal of a child from a parent with a disability is carried out on the basis of the person's disability, rather than incapacity to care for the child (Victorian Office of the Public Advocate 2012). The mere fact that the parent has a disability is often mistakenly taken for prima facie evidence that they are unable to be a good parent or pose a risk to the child (Frohmader).

\subsection{The Prevention of Sexual Abuse Argument}

This justification rests on the fact that women and girls with disabilities are particularly vulnerable to sexual abuse, and thus should be sterilised to prevent them from abuse and/or its consequences. For example, in Re Katie (1995) 128 FLR 194, it was said that the attractive looks of the girl made her more of a target for sexual predators, and this formed part of the Court's rationale for her to be sterilised at age 16. In other cases, the young girls' over-sexualised or inappropriate behaviour towards men was taken into account in authorising their sterilisation before menstruation (In re Elizabeth (1989) 96 FLR 248 ${ }^{15}$; Attorney-General (QLD) v Parents (In Re S) (1989) 13 Fam Lr 660).

15 In re Elizabeth (1989) 96 FLR 248. 
The incongruous nature of this rationale can be seen immediately: it is not about preventing abuse, but about preventing the consequences of abuse, i.e., unwanted pregnancies. Research has shown that sterilisation can actually increase the risk of sexual abuse rather than protect against it, as there is no chance of the individual becoming pregnant. This is especially so for women with psychosocial or intellectual disabilities, women in psychiatric or other institutions and women in custody (Committee on the Rights of Persons with Disabilities 2016; Sobsey and Doe 1991). Instead of taking appropriate measures to combat sexual abuse and the reasons why it occurs, sterilisation is used as a Band-Aid solution that places the responsibility on girls and women with disabilities for preventing the consequences that accompany it. As Stella Young so eloquently put it: 'the fact that this burden rests on the shoulders of some of our most vulnerable citizens is a disgrace; it's an insight into how people with disabilities, particularly women, are denied some of the most basic rights of personhood that should be afforded to all human beings, and we should be deeply ashamed of it' (Young 2013, p. 2).

\section{Should Forced Sterilisation Be Made Illegal?}

\subsection{Positions Taken by Stakeholders}

WWDA argue for an outright ban of involuntary sterilisation for women and girls with disabilities. 'Forced sterilisation is an act of violence, a form of social control and a clear and documented violation of the right to be free from torture. It is internationally recognized as a harmful practice based on tradition, culture, religion or superstition' (International NGO Council on Violence against Children 2012 as cited in Frohmader 2013, p. 8). They recognise that the issue is part of a more widespread pattern of denial of human and reproductive rights, which includes exclusion from appropriate health care, information and services (Dowse and Frohmader 2001 as cited in Frohmader 2013).

The CRPD Committee has formally asserted that involuntary sterilisation of women and girls with disabilities, and other kinds of reproductive discrimination, violates multiple provisions of the CPRD (Nowak 2008). It has urged state parties to abolish the administration of sterilisation of children and adults with disabilities without the full and informed consent of the individual concerned, including all forms of forced sterilisation, forced abortion and non-consensual birth control (Committee on the Rights of Persons with Disabilities 2013; Committee on the Rights of Persons with Disabilities 2016). In particular, the Committee has recommended that Australia 'enact national legislation prohibiting, except where there is a serious threat to life or health, the use of sterilisation of girls, regardless of whether they have a disability, and of adult women with disabilities in the absence of their fully informed and free consent' (Committee on the Rights of Persons with Disabilities 2013; Committee on the Rights of Persons with Disabilities 2016, p. 8).

The Australian Government argues that an outright ban is inappropriate, stating that it 'potentially denies the rights of persons with disabilities to access all available medical support on an equal basis with persons without a disability. It is a 'one size fits all' solution to a complex problem' (Senate Community Affairs References Committee 2013, p. 94). The Government suggests that all sterilisation should be banned where an individual has the capacity to consent, and if they may develop capacity to consent in the future, then irreversible sterilisation should be banned. It recommends that state and territory legislation regulating the sterilisation of adults with disabilities be amended to explicitly state that it is presumed that persons with disabilities have the capacity to make their own decisions unless objectively assessed otherwise. Finally, it submits that state and territory legislation be amended to clearly dictate that a court of tribunal does not have authority to hear an application for sterilisation where a person has legal capacity (Senate Community Affairs References Committee 2013).

\subsection{Forced Sterilisation Should Be Criminalised}

No woman or girl with a disability should ever be sterilised without her consent, save for very exceptional circumstances. Involuntary sterilisation is a form of violence, permits gross violations of 
human rights and puts Australia in breach of its international obligations. Urgent action must be taken to prevent the continued occurrence of this blatant disregard for human rights.

\subsubsection{Forced Sterilisation Is a form of Violence}

The sterilisation of a woman or girl without her consent is a form of violence. This is recognised by the Committee on the Rights of Persons with Disabilities (Committee on the Rights of Persons with Disabilities 2016) which has stated that forced, coerced and otherwise involuntary sterilisation may be considered not only violence, exploitation and abuse but also cruel, inhuman or degrading treatment or punishment. It is broadly recognized that forced sterilisation has life-long physical and psychological effects, 'permanently robbing women of the reproductive capabilities and causing severe mental pain and suffering' (Frohmader 2013, p. 60). By taking away such a basic bodily function as the ability to reproduce, the physical and mental wellbeing of a woman is adversely impacted and her physical and bodily integrity is violated (Sifris 2010 as cited in Frohmader 2013). Steele (Steele 2013) has called it 'legal violence', which is violence that is made possible by and sanctioned by the law.

It is concerning to note that, despite the significant amount of academic, medical and parental discourse around this issue, there is next to no discussion about sterilisation publicly available from women and girls with disabilities themselves. A prime example is the 2013 Senate Inquiry titled 'Involuntary or Coerced Sterilisation of People with Disabilities in Australia'. A clear majority of the submissions to the Senate Inquiry were made by disability activist bodies and parents arguing for and against forced sterilisation. There are a very limited number of case studies available to demonstrate the real and tangible harm that forced sterilisation causes to women and girls with disabilities. A small insight was provided at conference held by STAR, where women spoke of experiences such as "I went to hospital and instead of having my appendix out, I had a tubal ligation" and "after trying to have a baby for a long time I finally found out I had been sterilised when I was 14 living in an institution" (STAR 1991). These types of blatant violations of bodily integrity clearly fall within the ambit of violence and abuse. By not only failing to criminalise this practice, but authorising this form of violence to be perpetrated against both women and children, Australia is breaching article 16 of the CRPD.

Australia is further in breach of article 16 by declining to enact effective legislation and policies to ensure that the forced sterilisation of women and girls does not occur. Article 16 specifically mandates that gender-specific legislation and policies be enacted locally. There is currently no legislation prohibiting or even regulating the sterilisation of girls under 18 with disabilities. The legislation regulating the sterilisation of women over 18 with disabilities legalises this form of violence if the individual is deemed by a court not to have 'decision-making capacity', a notion that is arbitrary and decided on a case-by-case basis. This lack of effective legislation is unacceptable and falls far short of meeting the requirements of the CRPD.

Finally, article 16 explicitly dictates that state parties are to provide support and education to avoid, recognise and report instances of exploitation, violence and abuse. The failure to provide appropriate and sufficient assistance, support, information and education for women and girls with disabilities and their families and carers makes the current Australian position inconsistent with its obligations under the CRPD.

\subsubsection{Substituted Decision-Making Is Prohibited by the CRPD}

As well as the obvious breaches of article 16 mentioned above, the current capacity considerations and 'best interests' tests put Australia further in breach of its human rights obligations. Currently, there is a heavy focus on capacity considerations before an application for the sterilisation of a woman or girl with a disability can be authorised. If an individual is deemed not to have capacity, a decision is made about what is in her best interests according to the court. This means that 'in practice, the choices of women with disabilities, especially women with psychosocial or intellectual disabilities, are often ignored and their decisions are often substituted by those of third parties, including legal 
representatives, service providers, guardians and family members' (Committee on the Rights of Persons with Disabilities 2016, p. 11). This provision for substituted decision-making violates article 12 of the CRPD, which requires the provision of support for persons with disabilities to exercise their legal capacity. The UN Special Rapporteur on Torture has recently reiterated that the law should never distinguish between individuals on the basis of capacity or disability in order to permit sterilisation, specifically of girls and women with disabilities (Méndez 2013). Flynn and Arstein-Kerslake (Flynn and Arstein-Kerslake 2014) argue that upholding cognition as a prerequisite for personhood or the granting of legal capacity results in the exclusion of people with cognitive disabilities. 'Irrespective of decision-making ability, every person has an inherent right to legal capacity and equal recognition before the law' (Flynn and Arstein-Kerslake 2014, p. 83). This right to be recognized as a person before the law and have one's decisions legally recognized calls for a system of supported decision-making to replace the current substituted decision-making model that allows third parties to make decisions on behalf of individuals. Flynn and Arstein-Kerslake (Flynn and Arstein-Kerslake 2014) note that in recent years there has been growing support for the idea that almost every human being is able to express her will and preferences with the right support. They also argue that 'for the most part, we know very little about how people make decisions and, as a consequence, we should be slow to deny the right to have one's decisions respected by the law to anyone, even when it is difficult to decipher the person's wishes or where the individual has a different worldview, even one which may seem irrational or ill-formed' (Flynn and Arstein-Kerslake 2014, p. 82). The Committee on the Rights of Persons with Disabilities (Committee on the Rights of Persons with Disabilities 2016) has recognised that restricting or removing legal capacity can actually facilitate forced interventions, such as sterilization, abortion or contraception. As such, the current allowance for substituted decision-making is unacceptable.

The 'best interests' test has received a spate of criticism from disability rights advocates. Amnesty International Australia (Amnesty International Australia 2013, p. 44) maintain that the use of a best interests test is prohibited under international law, stating, 'claims that forcing or coercing women and girls into sterilisation is in their 'best interests' contradict the general principles of respect for inherent dignity, individual autonomy including the freedom to make one's own choices, and independence of persons set out in article 3(a) of the CRPD'. The main concern about the best interests test is that it is amorphous, undefined and slanted to give weight to the views and needs of carers (Senate Community Affairs References Committee 2013). It is a 'malleable concept that can fail to address the needs and human rights of persons with disabilities' (Senate Community Affairs References Committee 2013, p. 123). The test provides no adequate safeguards and may allow courts and tribunals to put the wishes of family members or carers above those of the individual with a disability. In the past, the best interests test has been used to justify the authorisation of sterilisations based on inappropriate considerations such as those mentioned in Section 5 of this paper. In reality, the best interests approach has little to do with the individual involved and more to do with the interests or wishes of others, in particular families and carers (Frohmader 2013). Legislative reform must be put into effect, which eliminates capacity considerations and implements a supported decision-making regime to prevent further violations of human rights.

\subsubsection{Exceptional Circumstances}

There are undoubtedly situations that give rise to a 'moral grey area' and make proposing legislative and policy reforms a toilsome task. These difficult cases necessitate exceptions to an outright ban on sterilisation without consent. This paper does not have the scope to consider a completely comprehensive solution to these controversial issues. However, they must be taken into consideration in any future legislative or policy reform in Australia.

The most obvious such circumstance is where an individual is in a coma or permanent vegetative state, and thus completely unable to make a decision (Flynn and Arstein-Kerslake 2014). Any new legislation would need to be flexible enough to allow for an exception in which a third party may make a decision on the basis of what the individual's will and preference would have been. This may be very 
difficult to ascertain, but difficulty should not preclude an effort to understand what the individual would have wanted in the circumstances.

Another problematic situation may arise where an individual refuses life-saving treatment. For example, if a woman with an intellectual disability is diagnosed with cancer and requires a hysterectomy to live, but refuses to undergo the operation, should the legislation be drafted such that she is allowed to refuse the treatment and ultimately die? It must be considered that women without disabilities have the right to refuse life-saving treatment, and as such, women with disabilities should be afforded the same right provided they have been supported in making an informed decision. Future legislative drafters would need to consider protecting medical practitioners who comply with the wishes of people with disabilities to refuse lifesaving treatment. Any legislation criminalising forced sterilisation would be otiose if medical practitioners were made liable for declining to perform a sterilisation procedure without the consent of an individual. Different considerations apply to minors. In general, minors are not considered able to make their own decisions in regards to medical treatment as they lack the necessary experience, knowledge and maturity ( $\left.\mathrm{O}^{\prime} \mathrm{Connor} 2009\right)$. A further exception may therefore be required for girls under the age of 18 where sterilisation without their consent is necessary due to a serious threat to their health or life.

\subsubsection{Other Factors in Favour of Criminalisation}

Whilst this paper does not have the scope to deeply delve into this complex subject, the interrelated issue of sexual autonomy weighs in favour of prohibiting forced sterilisation. The Australian Association of Development of Disability Medicine Inc. (Australian Association of Developmental Disability Medicine Inc. 2013, p. 1) has stated that, 'people with disabilities have the same rights as other people to exercise choices regarding sexual expression and relationships and have freedom over their body to make such choices'. The ability of individuals with disabilities to have their sexual and reproductive rights recognized on an equal basis with others should be taken into consideration when drafting rights-protecting legislation and reform.

\section{Recommendations}

As has been discussed, Australia's current legislative and policy framework regarding forced sterilisation of women and girls with disabilities is failing to protect those at risk of being sterilised without their consent. This paper proposes that a departure from the medical model ideology is needed, and that a new regime founded on the social model of disability should be developed. The social model recognises that disability results from the interaction between persons with impairments and the attitudinal and environmental barriers surrounding them (Parker 2012). This carries the implication that the environment must change to enable individuals living with a disability to participate in society on an equal basis with others. It recognises people with disabilities as an oppressed group in society and distinguishes between impairments and disability; disability being imposed on top of impairments by the way individuals are isolated and excluded from participating fully in society (Davis 2013). Thus, the focus should be shifted from performing a 'quick-fix' on the person who is seen as the problem, and placed on the environmental factors that are contributing to the issues that sterilisation is purportedly trying to address. This includes providing more support, education, resources and information to people with disabilities, their families and carers to enable them to better manage things such as menstruation and behavioural changes. It includes training for medical practitioners to try and change the archaic attitudes within the profession towards the sterilisation of people with disabilities. It includes a national uniform legislative regime to ensure that individuals are provided with consistent treatment regardless of geographical location. It includes the elimination of considerations of capacity and the 'best interests' of the individual, and the introduction of a supported decision making system to allow individuals to make informed decisions about sterilisation. It includes research to obtain a greater understanding of the prevalence of forced sterilisation in Australia. Furthermore, it includes harsher punishment for those who attempt to circumvent the formal procedures. 


\subsection{Support, Education, Resources and Information}

There is an appalling lack of support and resources available for people with disabilities to assist them with choices about relationships and sexuality, sexual and reproductive health and menstrual management (Senate Community Affairs References Committee 2013). Women with disabilities are often denied access to information, communication and education around these issues because of 'harmful stereotypes that assume that they are asexual and do not therefore require such information on an equal basis with others' (Committee on the Rights of Persons with Disabilities 2016, p. 10). Even where there are educational resources available, sex education is often not targeted appropriately, and is undermined by the message that people with disabilities are different and that sex education does not apply to them in the same way that it does to people without disabilities (Senate Community Affairs References Committee 2013). The increase of information, education and support in areas of sex, reproduction and menstruation for both individuals with disabilities and their carers will assist in alleviating some of the stresses that are experienced when dealing with matters such as menstrual management. The Senate has (rightly, in my opinion) recommended that such access to support services should be tailored to each individual, not a one-size-fits-all program (Senate Community Affairs References Committee 2013). An increased level of funding and devoted resources would assist in bridging the gap and providing individuals with disabilities and their families and carers the support they need to realise their rights on an equal basis with others. Further, it would bring Australia in line with its obligation under article 16 of the CRPD to provide support and resources to prevent instances of violence from occurring.

\subsection{Training for Medical Practitioners}

Medical practitioners are not presently provided with adequate education, training and professional development in relation to people with disabilities, sexual and reproductive health, informed consent, how to assess capacity, and how to communicate with people with disabilities and their carer or advocates effectively (Senate Community Affairs References Committee 2013). This is particularly problematic given that medical professionals are often influential in the decision to sterilise women and girls with disabilities (Frohmader 2013). The judgments of medical professionals are made from a particular perspective that women or girls with disabilities are basically the sum of their biology or physiology (Dowse and Frohmader 2001 as cited in Frohmader 2013). This ideology reinforces notions of the medical model and allows for medical professionals to hold the view that sterilisation will 'fix' the 'problems' that individuals face due to their impairments. Providing more effective education and training for medical practitioners will assist in re-shaping these misconceived attitudes and help to prevent instances of forced sterilisation occurring. This would also enable Australia to more effectively fulfil its obligations under article 16 of the CRPD.

\subsection{Legislative Reform}

Currently, it cannot be guaranteed that a person with a disability will receive the same treatment regardless of their geographic location. The principal differences between jurisdictions include the requirement of capacity as a threshold issue, the availability of legal representation and the factors considered when determining whether to authorise a sterilisation procedure (Senate Community Affairs References Committee 2013). Uniform national legislation should thus be developed to provide a coherent and consistent framework that criminalises sterilisation for girls, and for women without their free and informed consent. As mentioned, article 16 of the CRPD mandates that legislation be enacted to prevent instances of violence from occurring. Developing legislation to prohibit forced sterilisation would make Australia compliant with this requirement.

This paper will not attempt the arduous task of drafting proposed legislation. However, there are three matters that should undoubtedly be considered in drafting any future legislation: 
1. For the reasons submitted, considerations of capacity as a threshold issue should be eliminated. The provision for a substituted-decision making regime once an individual is deemed not to have capacity should also be excluded from any future legislation. Instead, a supported decision-making model should be developed to assist women with disabilities in making free and informed decisions about any sterilisation procedures. This would ensure that Australia realises its obligations under article 12 of the CRPD.

2. Following that, the 'best interests' test should be rejected. This test undermines human rights and would be redundant in a supported decision-making model.

3. As discussed, the provision of a small number of limited exceptions will be necessary to handle exceptional circumstances. These include where an individual does not have any ability to make a decision as they are in a coma or vegetative state, or, where a minor requires life-saving treatment. Any exceptions would need to be very carefully defined and limited in their scope to prevent the existing human rights violations arising from substituted decision-making from happening in the future.

It is vital that any drafters of future legislation keep in mind the general principle that women with disabilities, like all women, have the right to 'have control over and decide freely and responsibly on matters related to their sexuality, including sexual and reproductive health, free of coercion, discrimination and violence' (Committee on the Rights of Persons with Disabilities 2016, p. 10).

\subsection{Harsher Punishment for Those Trying to Circumvent Formal Procedures}

There have been reported instances of families taking their children to other jurisdictions to have them sterilized (Senate Community Affairs References Committee 2013). To address this issue, similar provisions to the Female Genital Mutilation (FGM) offences under the Crimes Act 1900 (NSW) ${ }^{16}$ could be adopted. Section 45 makes it an offence to aid, abet, counsel or procure a person to perform an FGM act on another person. It carries a penalty of imprisonment for 21 years. Section 45A makes it an offence to take a person or arrange for a person to be taken from the State with the intention of having FGM performed on that person. This also carries a penalty of imprisonment for 21 years. Similar provisions may be implemented to criminalise aiding, abetting or procuring a person to perform a sterilisation procedure on an Australian resident or taking an Australian resident outside of the State to have a sterilization procedure performed without consent. In addition to this, the Law Institute of Victoria (Law Institute of Victoria 2013) recommended that a system be put in place to allow the Australian Federal Police to put a child on an Airport Watch List if necessary. This would ensure that authorities were alerted if a family that had unsuccessfully applied for a sterilisation procedure were attempting to remove an individual from the country.

\subsection{Redress for Victims}

Article 16 of the CRPD requires that parties take appropriate measures to promote the recovery, rehabilitation and social reintegration of persons with disabilities who become victims of violence. After identifying that forced sterilisation is a form of violence, it is necessary that the Australian Government provide redress to the women and girls who have suffered from this practice. Whether this be in the form of an apology or compensation WWDA recommends that both occur (Frohmader 2013), it is appropriate that the Government publicly recognise that harm has been caused to the individuals affected, and attempt to assist these individuals in their rehabilitation.

16 Crimes Act 1900 (NSW). 


\subsection{Data Recording}

As mentioned, there is currently a substantial lack of information regarding the exact numbers of forced sterilisations that are occurring in Australia. The Government has not conducted any comprehensive reviews or research to shed light on this issue. It is therefore recommended that a uniform national approach to data recording be implemented to gain a more holistic understanding of the present number of sterilisations being performed and authorised in Australia.

\section{Conclusions}

Despite the copious attention that the issue of forced sterilisation of women and girls with disabilities in Australia has received from national and international stakeholders in recent years, little to no progress has been made. The Government remains apathetic and indifferent towards this issue. The persistent theme throughout this paper, and in recommendations from disability advocates and international bodies, is the violation of human rights. The current legislative and policy framework is impermissible from a human rights perspective. It puts Australia in breach of not only the CRPD, but almost all other human rights treaties to which it is a party. This paper has propounded that forced sterilisation is a form of violence. Legally authorising violence to be perpetrated against women and children with disabilities is unacceptable and cannot be allowed to continue in Australia. The prevention of this flagrant disregard for human rights begins with a national legislative scheme criminalising forced sterilisation. Coupled with further support and education for individuals with disabilities, their carers, and medical professionals, these reforms will provide a backbone for momentous progress in the Australian human rights sphere. Whilst the recommendations in this paper may not provide a complete and comprehensive solution to the issue of forced sterilisation, they will guide Australia down a path towards the ultimate goal: justice for the victims of this violence.

Conflicts of Interest: The author declares no conflict of interest.

\section{References}

ABC. 2003. Walk in our Shoes. Four Corners. June 16. Available online: http://www.abc.net.au/4corners/content/ 2003/transcripts/s880681.htm (accessed on 7 May 2016).

ABC. 2003. Interview with Chief Justice Alastair Nicholson. Four Corners. May 12. Available online: http://www. abc.net.au/4corners/content/2003/20030616_sterilisation/int_nicholson.htm (accessed on 17 June 2017).

Amnesty International Australia. 2013. Involuntary or Coerced Sterilisation of People with Disabilities in Australia. Submission No. 48 to Senate Community Affairs References Committee; Broadway: Amnesty International Australia.

Australian Association of Developmental Disability Medicine Inc. Involuntary or Coerced Sterilisation of People with Disabilities in Australia. Submission No. 59 to Senate Community Affairs References Committee; Brisbane: Australian Association of Developmental Disability Medicine Inc.

Australian Human Rights Commission. 2013. Involuntary or Coerced Sterilisation of People with Disabilities in Australia; Submission No. 5 to Senate Community Affairs References Committee; Sydney: Australian Human Rights Commission.

Brady, Susan M., and Sonia Grover. 1997. The Sterilisation of Girls and Young Women in Australia-A Legal, Medical and Social Context; Sydney: Australian Human Rights Commission.

Brady, Susan, John Britton, and Sonia Grover. 2001. The Sterilisation of Girls and Young Women in Australia: Issues and Progress; Sydney: Australian Human Rights Commission. Available online: https://www.humanrights.gov.au/our-work/disability-rights/projects/sterilisation-girls-andyoung-women-australia-issues-and (accessed on 8 May 2016).

Carter, John, and Merren Carter. 2013. Involuntary or Coerced Sterilisation of People with Disabilities in Australia. Submission No. 20 to Senate Community Affairs References Committee. Available online: https://sydney.edu.au/health-sciences/cdrp/Sterilisation_Submission\%2021.pdf (accessed on 8 May 2016). 
Committee on the Elimination of Discrimination against Women. 2010. Concluding Observations of the Committee on the Elimination of Discrimination against Women: Australia; Geneva: UN Committee on the Elimination of Discrimination against Women (CEDAW). Available online: http://www.refworld.org/docid/52dd07654. html (accessed on 8 May 2016).

Convention on the Elimination of all Forms of Discrimination against Women. 1981. Opened for signature 1 March 1980, 1249 UNTS 13 (entered into force 3 September 1981). Available online: http:/ /www.ohchr.org/ Documents/ProfessionalInterest/cedaw.pdf (accessed on 7 May 2016).

Convention on the Rights of Persons with Disabilities. 2008. Opened for signature 30 March 2007, 999 UNTS 3 (entered into force 3 May 2008). Available online: https://www.un.org/development/desa/ disabilities/convention-on-the-rights-of-persons-with-disabilities/convention-on-the-rights-of-personswith-disabilities-2.html (accessed on 7 May 2016).

Convention on the Rights of Persons with Disabilities: Declarations and Reservations (Australia). 2008. Opened for signature 30 March 2007, 999 UNTS 3 (entered into force 3 May 2008). Available online: http:/ /indicators. ohchr.org/ (accessed on 27 June 2017).

Committee on the Rights of Persons with Disabilities. 2011. Consideration of Reports Submitted by States Parties under Article 35 of the Convention, Concluding Observations of the Committee on the Rights of Persons with Disabilities_Spain; Geneva: UN Committee on the Elimination of Discrimination against Women (CEDAW). Available online: http:/ / www.refworld.org/docid/54992a7a4.html (accessed on 7 May 2016).

Committee on the Rights of Persons with Disabilities. 2013. Concluding Observations on the Initial Report of Australia; Geneva: UN Committee on the Elimination of Discrimination against Women (CEDAW). Available online: http:/ / www.refworld.org/docid/5280b5cb4.html (accessed on 17 June 2017).

Committee on the Rights of Persons with Disabilities. 2016. General Comment No. 3 (2016) on Women and Girls with Disabilities; $13^{\text {th }}$ sess. UN Doc CRPD/C/GC/3 25 November 2016. Geneva: UN Committee on the Elimination of Discrimination against Women (CEDAW). Available online: http://tbinternet. ohchr.org/_layouts/treatybodyexternal/Download.aspx?symbolno=CRPD/C/GC/3\&Lang=en (accessed on 7 May 2016).

Convention on the Rights of the Child. 1990. Opened for signature 20 November 1989, 1577 UNTS 3 (entered into force 2 September 1990). Available online: http:/ / www.ohchr.org/EN/ProfessionalInterest/Pages/CRC. aspx (accessed on 7 May 2016).

Committee on the Rights of the Child. 2005. Consideration of Reports Submitted by States Parties under Article 44 of the Convention, Concluding Observations: Australia. Available online: http:/ /www2.ohchr.org/english/ bodies/crc/docs/co/CRC_C_AUS_CO_4.pdf (accessed on 7 May 2016).

Committee on the Rights of the Child. 2012. Consideration of Reports Submitted by States Parties under Article 44 of the Convention, Concluding Observations: Australia; Geneva: Committee on the Rights of the Child (CRC). Available online: http://www2.ohchr.org/english/bodies/crc/docs/co/CRC_C_AUS_CO_4.pdf (accessed on 7 May 2016).

Davis, Lennard J. 2013. The Disability Studies Reader, 4th ed. London: Routledge.

Dowse, Leanne. 2004. Moving Forward or Losing Ground? The Sterilisation of Women and Girls with Disabilities in Australia. Paper presented at the Disabled Peoples' International (DPI) World Summit, Winnipeg, MB, Canada, September 8-10. Available online: http://wwda.org.au/issues/sterilise/sterilise2001/steril3/ (accessed on 8 May 2016).

Family Law Council. 1994. Sterilisation and Other Medical Procedures on Children; Melbourne: Family Law Council. Available online: https:/ / www.ag.gov.au/FamiliesAndMarriage/FamilyLawCouncil/Documents/ Sterilisation\%20and\%20Other\%20Medical\%20Procedures\%20on\%20Children.doc (accessed on 8 May 2016).

Flynn, Eilionoir, and Anna Arstein-Kerslake. 2014. Legislating personhood: Realising the right to support in exercising legal capacity. International Journal of Law in Context 10: 81-104. [CrossRef]

Frohmader, Carolyn. Parenting Issues for Women with Disabilities in Australia: A Policy Paper; Tasmania: Women with Disabilities Australia. Available online: http://wwda.org.au/wp-content/uploads/2013/12/ parentingpolicypaper09.pdf (accessed on 8 May 2016).

Frohmader, Caroyln. 2013. Involuntary or Coerced Sterilisation of People with Disabilities in Australia. Submission No. 49 to Senate Community Affairs References Committee; Canberra: Senate Community Affairs Committee Secretariat. 
Frohmader, Carolyn. 2014. Fact Sheet: Forced Sterilisation; Tasmania: Women with Disabilities Australia. Available online: https:/ / www.pwd.org.au/documents/temp/FS_Sterilization.pdf (accessed on 10 March 2016).

International Convention on Civil and Political Rights. 1976. Opened for signature 19 December 1966, 993 UNTS 171 (entered into force 23 March 1976). Available online: http://www.ohchr.org/Documents / ProfessionalInterest/ccpr.pdf (accessed on 7 May 2016).

International Covenant on Economic, Social and Cultural Rights. 1976. Opened for signature 19 December 1966, 993 UNTS 3 (entered into force 3 January 1976). Available online: http://www.ohchr.org/EN/ ProfessionalInterest/Pages/CESCR.aspx (accessed on 7 May 2016).

International NGO Council on Violence against Children. 2012. Violating Children's Rights: Harmful Practices Based on Tradition, Culture, Religion or Superstition. A report from International NGO Council on Violence against Children. New York: International NGO Council on Violence against Children. Available online: http://srsg.violenceagainstchildren.org/document/_844 (accessed on 7 May 2016).

Law Institute of Victoria. 2013. Involuntary or Coerced Sterilisation of People with Disabilities in Australia. Submission No. 79 to Senate Community Affairs References Committee; Melbourne: Law Institute of Victoria.

Méndez, Juan E. 2013. Report of the Special Rapporteur on Torture and Other Cruel, Inhuman or Degrading Treatment or Punishment. 22 ${ }^{\text {nd }}$ sess. Agenda Item 3, UN Doc A/HRC/22/53 (1 February 2013). Available online: http:/ / www.ohchr.org/Documents/HRBodies/HRCouncil/RegularSession/Session22/A.HRC. 22.53_English.pdf (accessed on 7 May 2016).

Naik, Lesley. 2012. When is the sterilisation of an intellectually disabled child "therapeutic"? A practical analysis of the legal requirement to seek court authorisation. Journal of Law and Medicine 20: 453-63. [PubMed]

Nowak, Manfred. 2008. Report of the Special Rapporteur on Torture and other Inhuman or Degrading Treatment or Punishment. $7^{\text {th }}$ sess. Agenda Item 3, UN Doc A/HRC/7/3. 15 January 2008. Available online: http: //www.ohchr.org/EN/Issues/Torture/SRTorture/Pages/SRTortureIndex.aspx (accessed on 31 May 2017).

O'Connor, Christopher M. 2009. What rights do minors have to refuse medical consent? Journal of Lancaster General Hospital 4: 63-65.

Office of the Public Advocate. 2013. Involuntary or Coerced Sterilisation of People with Disabilities in Australia. Submission No. 14 to Senate Community Affairs References Committee; Carlton: Office of the Public Advocate.

Parker, Malcolm. 2012. Bioethical Issues: Forced Sterilisation: Clarifying and challenging intuitions and models. Journal of Law and Medicine 20: 512-27.

People with Disabilities Australia. 2013. Involuntary or Coerced Sterilisation of People with Disabilities in Australia. Submission No. 50 to Senate Community Affairs References Committee; Redfern: People with Disabilities Australia.

Rhoades, Helen. 1995. Intellectual Disability and Sterilisation-An Inevitable Connection? Australian Journal of Family Law 9: 234-52.

Senate Community Affairs References Committee, Parliament of Australia. 2013. Involuntary or Coerced Sterilisation of People with Disabilities in Australia; Canberra: Commonwealth of Australia. Available online: http://www.aph.gov.au/Parliamentary_Business/Committees/Senate/Community_ Affairs/Involuntary_Sterilisation/First_Report (accessed on 10 March 2016).

Shakespeare, Tom. 2002. The social model of disability: an outdated ideology? Research in Social Science and Disability 2: 9-28.

Sobsey, Dick, and Tanis Doe. 1991. Patterns of sexual abuse and assault. Sexuality and Disability 9: 243-59. [CrossRef]

Spicer, Cathy. 1999. Sterilisation of Women and Girls with Disabilities-A Literature Review; Tasmania: Women with Disabilities Australia. Available online: http://wwda.org.au/issues/sterilise/sterilise1995/steril/ (accessed on 7 May 2016).

Standing Committee of Attorneys-General. 2008. Communique. March 28. Available online: http://www.nswbar. asn.au/circulars/scag.pdf (accessed on 31 May 2017).

STAR. 1991. On The Record-A Report on the 1990 STAR Conference on Sterilisation: 'My Body, My Mind, My Choice'; Melbourne: Victorian Action on Intellectual Disability (STAR). Available online: http://wwda.org.au/ issues/sterilise/sterilise1995/record/ (accessed on 17 June 2017).

Steele, Linda. 2008. Making sense of the Family Court's decisions on the non-therapeutic sterilisation of girls with intellectual disability. Australian Journal of Family Law 22: 1-23. 
Steele, Linda. 2013. Involuntary or Coerced Sterilisation of People with Disabilities in Australia. Submission No. 44 to Senate Community Affairs References Committee; February 24. Available online: http:/ / www. aph.gov.au/DocumentStore. ashx?id=9880795d-9a5b-4a00-8614-72fb4bad7b6a\&subId=16147 (accessed on 7 May 2016).

UN General Assembly Human Rights Council. 2011. Draft Report of the Working Group on the Universal Periodic Review: Australia; 10 ${ }^{\text {th }}$ sess. UN Doc A/HRC/WG.6/10/L. 8 (3 February 2011). Available online: https://www.ag.gov.au/RightsAndProtections/HumanRights/United-Nations-HumanRights-Reporting/Documents/UniversalPeriodicReview-ReportoftheWorkingGroup.pdf (accessed on 27 June 2017).

Victorian Office of the Public Advocate. 2012. The Removal of Children from Their Parent with a Disability. Position Statement; Carlton: Office of the Public Advocate.

Victorian State Government. 2016. Penalties and Values (11 March 2016) Justice and Regulation. Available online: http:/ / www.justice.vic.gov.au/home/justice+system/fines+and+penalties/penalties+and+values / \#breadcrumbs (accessed on 10 May 2016).

World Health Organisation. 2014. Eliminating Forced, Coercive and Otherwise Involuntary Sterilisation: An Interagency Statement; Geneva: World Health Organisation. Available online: http:/ /www.unaids.org/sites/default/ files/media_asset/201405_sterilization_en.pdf (accessed on 7 May 2016).

World Medical Association and the International Federation of Health and Human Rights Organisations. 2011. Global Bodies Call for end to Forced Sterilisation. Press Release. 5 September 2011. Available online: http:/ / wwda.org.au/issues/sterilise/sterilise2011/sterilwma2011/ (accessed on 7 May 2016).

Young, Stella. 2013. Involuntary or Coerced Sterilisation of People with Disabilities in Australia. Submission No. 68 to Senate Community Affairs References Committee.

(C) 2017 by the author. Licensee MDPI, Basel, Switzerland. This article is an open access article distributed under the terms and conditions of the Creative Commons Attribution (CC BY) license (http:/ / creativecommons.org/licenses/by/4.0/). 